Send your letters to the editor, British Dental

Journal, 64 Wimpole Street, London W1G 8YS

Emailbdj@bda.org

Priority will be given to letters less than 500

words long. Authors must sign the letter,

which may be edited for reasons of space

\section{Occlusal factors}

Sir,- I very much enjoyed the article by Holbrook, Arnadottir and Kay Prevention of tooth wear (BDJ 2003, 195: 75). Their review of the subject and its measurement, historical and geographic perspective gives rise to questions which beg to be answered. We owe them a debt in bringing this subject to the table.

From my own practice, and those practices and dental schools I've had the good fortune to be affiliated with, I feel tooth wear is a problem of endemic proportions 'waiting to be discovered by the masses'. It has been my experience that parafunction and its sequelae result in decreasing the quality of life of so many of our patients and enormous preventable destruction of tooth tissue (not to mention the periodontium and TMJ).

The question I felt arose from the paper was that of the occlusal factors involved (I realise that the ' 0 ' word causes great emotion and debate), but felt that in addition to the excellent recommendations made; evaluation diagnosis and dare I say, 'treatment' of parafunctional habits (primarily bruxing and clenching) can also be of enormous value to our patients in the prevention of tooth wear.

\section{S. Bray \\ Poole}

doi: 10.1038/sj.bdj.4810747

\section{Patient attendance}

Sir,- I read the paper by Can et al, The use of postal reminders to reduce nonattendance at an orthodontic clinic: A randomised controlled trial (BDJ 2003 195: 199) with interest.

However, for hospital departments suffering from similarly poor new patient attendance levels, I would recommend telephone reminders as a simpler alternative.

Before instigating a reminder system in my department, an average of 24 per cent (S.D. 5.2) of patients failed to attend new patient clinics each month, excluding cancellations. Since starting telephone reminders in the week preceding an appointment, the monthly failure to attend rate has dropped to an average of 11 per cent (S.D. 5.9). Patients' telephone numbers are requested from referring practitioners as essential information on our standardised referral forms.

We find that the savings made from reducing wasted clinician time more than compensate for the small amount of the receptionist's time used. If the telephone call reveals that a patient will not attend, the receptionist can immediately call patients on the waiting list and the gap is usually filled.

This would appear to give greater control over the clinic than the system suggested by Can et al. They

recommended that as non-return of a reminder indicates that the patient might not attend, another patient could be booked in.

There is a risk that both patients might attend and then the clinic would be overbooked. The repeated mailings also take time, and so short-notice cancellations can be difficult to address. The telephone reminder system avoids these problems, and for local rate calls the costs are small compared with the savings made.

S. J. Nute

Essex

doi: $10.1038 /$ sj.bdj.4810748

\section{GP and GDP fee scales}

Sir,- I have currently been researching the discrepancies in salaries between salaried GPs and salaried GDPs. After looking at both BMA and BDA websites it dismays me to see the difference in how these different bodies represent their members.

The BMA presents evidence to the DDRB stating that 'salaried GPs' salaries should reflect predominantly that of hospital consultants.' The BMA suggest a fee scale of between $£ 45-68 \mathrm{k}$. From checking the adverts for salaried GPs in the press, this would appear to be what most employers are offering.

The BDA's evidence however seems to be happy with the DDRB giving a measly rise to salaried GDPs which would leave them approximately £20k worse off than their medical counterparts using the current salary scale of LA1.

The BDA concentrates on differences between other areas of the professional but seems to have forgotten that within the NHS there is supposed to be equivalence between medics and dentists. I wonder what other readers and BDA members think of this situation.

R. Emanuel

Surrey

The BDA's Industrial Relations Team responds:

Salaried GDP remuneration has equivalence to remuneration across the salaried primary dental care services. As Dr Emanuel points out however, this can result in discrepancies between salaried GMPs and GDPs.

For some time, there have been signals from the English Health Department that the role of salaried GDPs in England (the SGDP role in Scotland is firmly established) was likely to be phased out. Experience however suggests that, on the contrary, the salaried GDP resource is in fact in considerable demand with Trusts, some of whom have experienced real recruitment difficulties.

The BDA is therefore working with the Department of Health on their Review of Salaried Primary Dental Care Services in England, whose terms of reference, building on the principles of Agenda for Change for non-medical NHS staff groups, aim to develop 'a clear future direction for the salaried primary care dental service, consistent with Shifting the Balance of Power and Options for Change;

Competences, roles, education and training and career pathways for salaried primary care dentists; (and) a revised pay and grading structure to support that direction.' The review will:

- Set the contribution of salaried dentists within the overall context of primary care dentistry, taking into account the contribution of other members of the dental team; 
- Provide fair reward for the duties and responsibilities attached to a particular post;

- Provide for full recognition of the differences in job weight across the salaried primary care dental service;

- Provide incentives for dentists to give of their best and reward those who give the most to the NHS;

- Be consistent with pay and pay principles for other staff groups, including Equal Pay Legislation;

- Provide a clear career structure, with appropriate 'stopping off' points which fit with the needs of the NHS and fits with the aspirations of salaried primary care dentists;

- Provide a pay system which reflects and rewards career progression, providing an incentive for dentists to achieve their full potential;

- Allow for current salaried primary care dentists to move across to the new career and pay structure (and actively encourage them to do so);

- Take account of the need for specialisation in salaried dental services outside hospitals and ensure consistency with the principles of delivery of specialist services elsewhere in medicine and dentistry;

- Need to also address pensions and the reality of portfolio careers so that if dentists move between salaried and independent work there is a level playing field.

Both parts of the report will be published, together with the Government's response. The review is scheduled to address issues of service organisation, management/leadership and size in its first phase and will go on to examine issues of competencies, roles, education, training and career pathways.

The work on pay and conditions of service is scheduled to be taken forward in 2004/05, and the BDA, which is directly represented on the Review Steering Group by Janet Clarke and Eric Rooney (Chair and Vice-Chair of CCCPHD), will be aiming to ensure that the position and roles of all salaried primary care dentists including salaried GDPs - is protected and advanced throughout this process.

Industrial Relations Team

BDA

doi: 10.1038/sj.bdj.4810749

\section{Stoned}

Sir,- Circa 30 years ago a patient presented for new Full/Full dentures. When I examined him I saw a large sailolith in his right submandibular salivary gland duct. He was unaware of it!

Under local anaesthetic I first put in a suture distal to it, then incised the floor of the mouth to 'deliver' it. I removed the distal suture and placed three sutures to close my incision. Healing was uneventful. I think this example (below measured in $\mathrm{cm}$ ) is slightly larger and greater in girth than the Trinidad and Tobago example (BDJ 2003, 195: 175) despite having lost some of its extremity due to drying out!

Interestingly, the patient was Afro Carribean. Can Suffolk claim the record? J. F. Sharp Ipswich doi: 10.1038/sj.bdj.4810750

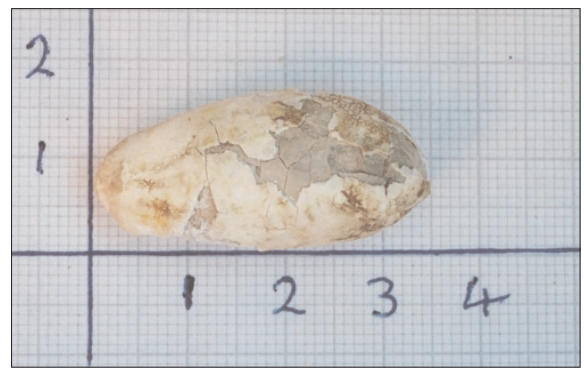

Sir,- In answer to a question posed previously by Dr's Al-Bayathy, Scipio, and Matthews (BDJ 2003, 195: 175 ) regarding record size for sialoliths, this large sialolith was also removed under local anaesthesia. (see picture below measured in $\mathrm{cm}$ )

P. Keogh

S. Flint

Dublin

doi: 10.1038/sj.bdj.4810751

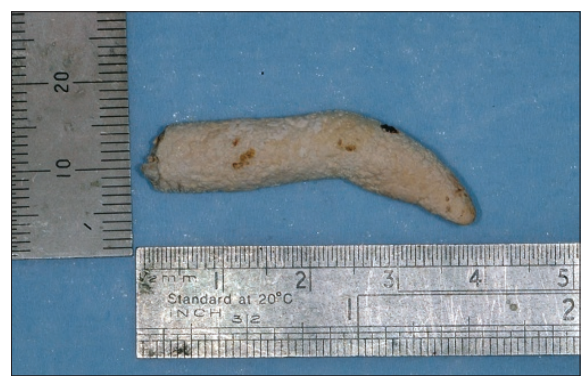

\section{Online CPD}

Sir,- I have just finished my first session of online CPD with the new BDA/Eastman initiative launched in the recent issues of the $B D J$. I felt that I must write to you to congratulate you and your colleagues on a fantastic piece of work.

I have been extensively involved in the organisation and provision of CPD for a number of years now, and it has always been somewhat difficult to really achieve the aims of the CPD process.

This initiative is a major step forwards, and I will be recommending it to all my colleagues.

T. Thayer

By email

doi: 10.1038/sj.bdj.4810752 


\section{Late dental nurse remembered}

December 2003

The 2003 Premier Symposium

Date: 06.12 .03

Venue: Kings College, London

Contact: Laura Miles, Dental Protection

Tel: +44 (0) 2073991339

E-mail: laura.miles@mps.org.uk

Did you miss this? An update on recent law

Date: 12.12 .03

Venue: British Dental Association Lecture

Theatre, London

Contact: Kath Blackler, Events Office

Tel: +44 (0) 2075634590

E-mail: events@bda.org

\section{March 2004}

2nd Asia Pacific Congress on Craniofacial

Distraction Osteogenesis

Date: 5-10.03.04

Venue: Maldives

Contact: www.distraction2004.com

E-mail: secretary@distraction2004.com

\section{May 2004}

British Dental Conference and Exhibition

Date: 06.05.04 - 08-05.04

Contact: Events Office,

British Dental Association

Venue: Bournemouth International

Centre

Tel: +44 (0) 2075634590

Fax: +44 (0) 2075634591

E-mail: events@bda.org

A training bursary was launched last month by community health chiefs to mark the memory of a dedicated Oldham dental nurse who died earlier this year.

Naveed Maqsood (23), who died of cancer in June, was working at John Scott's dental practice in Lees. Previously, Naveed had spent two years on a bilingual dental nurse training programme run by Oldham Primary Care Trust, which saw him work at six practices in the town centre, Lees and Chadderton areas, along with other placements

The bilingual dental nursing training programme was introduced to improve services to patients speaking Urdu, Bangla or other languages, and to raise awareness among communities of the NHS career options. The training bursary will build on this work by offering additional opportunities to community-based NHS staff who are bilingual, whether they work in dentistry or other areas.

The bursary will provide $£ 1,000$ annually to help fund training opportunities, or purchase training materials including textbooks. The bilingual dental nursing

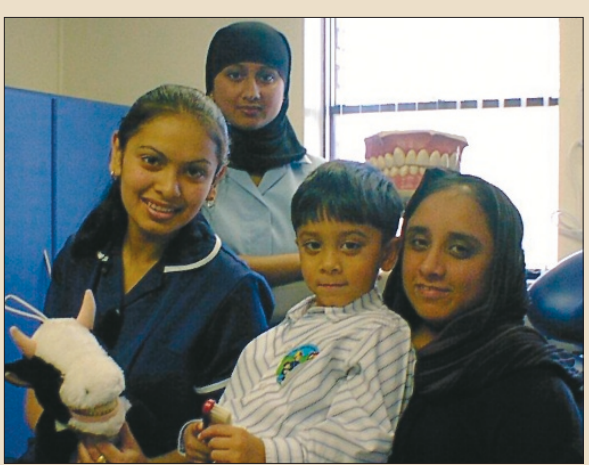

From left to right: Dental nurses Rayhana Khatun and Joohora Begum, who are both on the scheme, Abdullah (Naveed's son) and Jamilla (Naveed's wife)

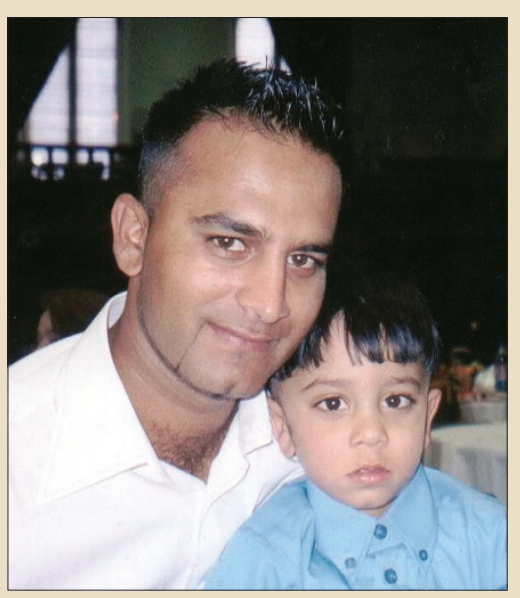

Naveed Maqsood with son Abdullah scheme was started in 2001, and was funded by the Oldham NHS Trust.

Oldham PCT took over funding of the scheme when it was created on 1 April 2002. So far, seven trainees have taken part in the scheme, which includes placements at both general dental practices and other specialist centres.

PCT staff who meet criteria including a good knowledge and understanding of issues faced by Oldham's communities and fluency in English and either Urdu, Bangla, Punjabi or Pushto can apply for grants from the Naveed Maqsood training bursary. 